\title{
Urinary C-Peptide Secretion(UCPS): Can It be A New Index to Reflect Insulin Sensitivity and A Predictor in Pregnant Women?
}

\section{Zhang Wei}

Jiangsu Province Hospital and Nanjing Medical University First Affiliated Hospital

https://orcid.org/0000-0002-8892-4018

Minmin An

suhu city second people's hospital

Qi Fu

first affilated hospital of nanjing medical university

Xiaohua Men

wuhu city second people's hospital

Yinhui He

first affiliated hospital of nanjing medical university

Tao Yang ( $\nabla$ dryangtao@icloud.com )

https://orcid.org/0000-0001-6375-3622

Research article

Keywords: Gestational diabetes mellitus, Urinary C-peptide secretion, Insulin sensitivity, BMI

Posted Date: July 15th, 2020

DOl: https://doi.org/10.21203/rs.3.rs-38670/v1

License: (c) (i) This work is licensed under a Creative Commons Attribution 4.0 International License.

Read Full License 


\section{Abstract}

Background: In order to assess the correlation between pregnant women's urinary C-peptide secretion(UCPS) and insulin sensitivity, and to examine the predictors of gestational diabetes.

Methods: we recruited 166 women between 20 and 28 weeks of gestation. Their height and weight were measured to calculate the body mass index (BMI). 75g OGTT was carried out, so as to detect the serum glucose, serum insulin and C-peptide levels. Besides, the homeostasis model assessment of insulin resistance (HOMA-IR), homeostasis model assessment of $\beta$ cell function (HOMA- $\beta$ ), Matsuda index, and area under the serum C-peptide curve (CPauc) were calculated. Additionally, the fasting urine specimen and all urine samples within 2 hours after OGTT were collected to determine the urinary C-peptide and urine volume to calculate UCPS.

Results: We found that Fasting serum insulin (Fins), Fasting serum C-peptide (FCP), BMI, OGTT 2h UCPS(UCPS120), CPauc, Matsuda index and HOMA-IR of GDM group were higher than NGT group. FCP was correlated with UCPSO $(r=0.234, p=0.002)$ and HOMA- $\beta(r=0.251, p=0.001)$. UCPS120 was correlated with CPauc $(r=0.176 p<0.001)$, Matsuda index $(r=-0.362, p<0.001)$ and HOMA-IR( $r=0.336, p<0.001)$. The combination of BMI and UCPS120 was better than other index in predicting GDM, with a sensitivity of $72.0 \%$ and specificity of $70.7 \%$.

Conclusion: UCPS120 had the potential to be a new index to reflect insulin sensitivity in pregnant women. To screening the GDM, the combination of BMI and UCPS120 was better than other index.

\section{Background}

Gestational diabetes mellitus (GDM) is a global health problem, which is mainly caused by impaired insulin action and $\beta$-cell dysfunction [1]. With the progress of pregnancy, maternal insulin sensitivity decreases by about 60 percent [2], and the increasing insulin antagonistic hormone will lead to maternal hyperinsulinemia [3]. In clinical practice, measuring insulin secretion is relatively straightforward using HOMA- $\beta$ and CPauc. Matsuda index and HOMA-IR are commonly used to evaluate the insulin sensitivity $[4,5]$.

To diagnose GDM and evaluate the islet function of pregnant women, we usually use the serum glucose, insulin and C-peptide detected in three or more points during OGTT. There are a number of clinical studies to explore relatively simplified indicators. Urinary $C$ peptide is a non-invasive, easily operative, and highly acceptable index [6]. Studies have shown that Urinary $\mathrm{C}$ peptide creatinine ratio (UCPCR) is a practical and non-invasive method to assess insulin secretion $[7,8]$. But urine creatinine is easily affected by muscle content, which may lead to a higher UCPCR in women[9]. So our study first attempted to use postprandial urinary C-peptide secretion(UCPS) to assess islet function in pregnant women between 20 and 28 weeks of gestation, and to investigate whether it can be used as an indicator for GDM screening.

\section{Methods}




\subsection{Objects}

Pregnant Han nationality women at 20-28 gestational weeks (according to Chinese Diabetes Society 2017 guidelines) undergoing routine checks in the outpatient department of our hospital from January 2017 to December 2017 were selected. All of them were preliminarily screened for the $75 \mathrm{~g}$ OGTT to collect the fasting, $1 \mathrm{~h}$ and $2 \mathrm{~h}$ plasma as well as urine specimens. All participants were then divided into GDM group and NGT group according to the serum glucose level. Those previously diagnosed with diabetes, combined with acute infection, taking glucocorticoids within the past 2 weeks, and combined with other chronic disease were excluded. This study was approved by Ethics Committee, and all enrolled participants had signed the informed consent.

Diagnostic criteria of GDM: according to the recommendations of the guidelines from (2017): pregnant women conforming to any one of the following criteria could be diagnosed: $F B G \geq 5.1 \mathrm{mmoL} / \mathrm{L}$ (92mg/dL), $75 \mathrm{~g}$ OGTT $1 \mathrm{~h}$ serum glucose $\geq 10.0 \mathrm{mmoL} / \mathrm{L}(180 \mathrm{mg} / \mathrm{dL})$ or $75 \mathrm{~g}$ OGTT $2 \mathrm{~h}$ serum glucose $\geq 8.5 \mathrm{mmoL} / \mathrm{L}(153 \mathrm{mg} / \mathrm{dL})$.

\subsection{Methods}

Q1هGeneral clinical data collection: the age, family history of diabetes, history of GDM, previous medical history, gestational week $(\mathrm{w})$, height $(\mathrm{m})$, and current weight $(\mathrm{kg})$ of all enrolled pregnant women were recorded. Meanwhile, the current body mass index $\left(\mathrm{BMI} \mathrm{kg} / \mathrm{m}^{2}\right)$ was calculated.

$\triangle 2 \triangle B$ Blood specimen collection and determination: for all enrolled pregnant women, $5 \mathrm{ml}$ fasting blood was collected at 8:00 in the morning after an 8h overnight fast, so as to determine the FBG, blood lipid, liver and kidney function, glycated hemoglobin (HbA1c), fasting insulin (FIns), and fasting C-peptide (FCP). After fasting blood collection, $75 \mathrm{~g}$ oral glucose tolerance test (OGTT) was taken, the venous blood was collected at $1 \mathrm{~h}$ and $2 \mathrm{~h}$ respectively, so as to determine the serum glucose, serum insulin and serum Cpeptide at corresponding time points.

\3ХUrine specimen collection and determination: the fasting urine (the participants should passed their overnight first void urine before OGTT), as well as urine at OGTT $2 \mathrm{~h}$ (all urine should be collected until $2 \mathrm{~h}$ after taking the glucose) were collected. No food was allowed during the OGTT, while water was allowed. The urine volume should be recorded each time, and $10 \mathrm{ml}$ urine should be retained, which was transferred to the $5 \mathrm{ml}$ frozen tubes and preserved in the refrigerator at $-80^{\circ} \mathrm{C}$ until detection.

\4هDetermination of related indexes: Determination of serum insulin, serum C-peptide and urine C peptide: chemiluminescent immunoassay (IMMULITE 2000 analyzer, Siemens); serum glucose determination: glucose oxidase method (AU5800 biochemical analyzer, Beckmann); HbA1c determination: high pressure liquid chromatography (HPLC) (Arkray HA-8180 full- automatic glycated hemoglobin analyzer, Arkray Kabushiki gaisha); and urine creatinine determination: picric acid method (AU5800 biochemical analyzer, Beckmann). 


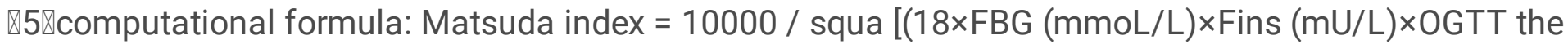
average serum glucose $(\mathrm{mmoL} / \mathrm{L}) \times O G T T$ the average insulin $(\mathrm{mU} / \mathrm{L})$ )] $\times$ HOMA-IR (homeostasis model of insulin resistance index) $=$ Fins $(\mathrm{mU} / \mathrm{L}) \times F B G(\mathrm{mmoL} / \mathrm{L}) / 22.5 ; \mathrm{HOMA}-\beta$ (homeostasis model of insulin secretion index) $=[20 \times$ Fins $(\mathrm{mU} / \mathrm{L})] /[$ FBG $(\mathrm{mmoL} / \mathrm{L})$ - 3.5]; UCPS (product of urine volume and urinary $\mathrm{C}$ peptide) $(\mathrm{ug})=\mathrm{UCP}(\mathrm{ng} / \mathrm{mL}) \times$ urine volume $(\mathrm{mL}) / 1000$.

\subsection{Statistical analysis}

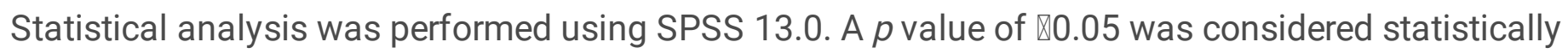
significant. Measurement data were expressed as mean \pm standard deviation, and inter-group comparison was carried out using $t$ test. For non- normal distribution data, Mann-Whitney $U$ test was employed for comparison. The Pearson correlation coefficient and linear regression models were adopted for correlation analysis. Receiver operator characteristic curve (ROC) was used to assess the predictive ability for GDM of each index.

\section{Results}

3.1. General information of participants (Table 1): 166 pregnant women were enrolled into this study, which were all Han nationality. 41 were diagnosed with GDM, 21 with family history of diabetes, accounting for $24.7 \%$ and $12.7 \%$ of all participants, respectively. There were no significant differences in age, gestational age and family history of diabetes between the two groups. 
Table 1

Participants Characteristics and comparisons between two groups

\begin{tabular}{|c|c|c|c|c|c|}
\hline & Min & Max & $\begin{array}{l}\text { NGT } \\
(N=125)\end{array}$ & $\begin{array}{l}\text { GDM } \\
(\mathrm{N}=41)\end{array}$ & $p$ \\
\hline Age(years) & 21 & 40 & $27.70 \pm 3.66$ & $28.20 \pm 3.84$ & 0.462 \\
\hline Gestational age(weeks) & 20 & 28 & $25.51 \pm 1.42$ & $25.85 \pm 1.68$ & 0.475 \\
\hline $\begin{array}{l}\text { Family history of } \\
\text { diabetes(\%) }\end{array}$ & / & / & $15(12.0 \%)$ & $6(14.6 \%)$ & 1.000 \\
\hline $\mathrm{BMI}\left(\mathrm{kg} / \mathrm{m}^{2}\right)$ & 16.02 & 34.38 & $20.31 \pm 2.71$ & $22.13 \pm 2.63$ & $\begin{array}{l}< \\
0.001^{* *}\end{array}$ \\
\hline Fins(uU/mL) & 2.04 & 46.04 & $7.42 \pm 3.22$ & $10.40 \pm 6.84$ & $0.014^{*}$ \\
\hline $\mathrm{FCP}(\mathrm{ng} / \mathrm{mL})$ & 0.72 & 6.14 & $1.87 \pm 0.67$ & $2.51 \pm 0.84$ & $0.001^{* *}$ \\
\hline $\mathrm{FBG}(\mathrm{mmoL} / \mathrm{L})$ & 4.09 & 6.01 & $4.62 \pm 0.25$ & $5.23 \pm 0.31$ & $\begin{array}{l}< \\
0.001^{* *}\end{array}$ \\
\hline Ins60(uU/mL) & 12.67 & 352.66 & $52.90 \pm 36.97$ & $71.42 \pm 56.92$ & 0.076 \\
\hline CP60(ng/mL) & 3.59 & 35.62 & $9.94 \pm 3.73$ & $12.20 \pm 5.02$ & $0.016^{*}$ \\
\hline $\mathrm{BG} 60(\mathrm{mmoL} / \mathrm{L})$ & 4.05 & 11.90 & $7.31 \pm 1.43$ & $9.09 \pm 1.62$ & $\begin{array}{l}< \\
0.001^{* *}\end{array}$ \\
\hline Ins120(uU/mL) & 10.37 & 315.45 & $51.27 \pm 36.28$ & $73.27 \pm 56.22$ & 0.114 \\
\hline CP120(ng/mL) & 4.61 & 22.97 & $10.95 \pm 4.00$ & $12.70 \pm 4.60$ & 0.135 \\
\hline $\mathrm{BG} 120(\mathrm{mmoL} / \mathrm{L})$ & 3.95 & 9.32 & $6.55 \pm 0.94$ & $7.68 \pm 1.26$ & $\begin{array}{l}< \\
0.001^{\star *}\end{array}$ \\
\hline
\end{tabular}

${ }^{\star} p<0.05 ;{ }^{* *} p<0.01$

BMI: body mass index;GDM: Gestational Diabetes Mellitus;HbA1c: Glycosylated hemoglobin;

Fins: Fasting Insulin; Ins60: OGTT 1-Hour Insulin; Ins120: OGTT 2-Hour Insulin;

FCP: Fasting C peptide; CP60: OGTT 1-Hour C peptide; CP120: OGTT 2-Hour C peptide;

FBG: Fasting Glucose; BG60: OGTT 1-Hour Glucose; BG120: OGTT 2-Hour Glucose;

UCPS0: Fasting UCPS; UCPS120: OGTT 2Hour UCPS;

HOMA- $\beta$ : Homeostasis model assessment of beta cell function;

HOMA-IR: Homeostasis model assessment for insulin resistance;

CPauc: C peptide area under the curve; INSauc: Insulin area under the curve. 


\begin{tabular}{|c|c|c|c|c|c|}
\hline & Min & Max & $\begin{array}{l}\text { NGT } \\
(N=125)\end{array}$ & $\begin{array}{l}\text { GDM } \\
(N=41)\end{array}$ & $p$ \\
\hline UCPSO(ug) & 0.36 & 27.86 & $4.76 \pm 4.57$ & $5.74 \pm 4.19$ & 0.510 \\
\hline UCPS120(ug) & 1.19 & 51.37 & $11.34 \pm 65.06$ & $17.36 \pm 10.78$ & $0.033^{*}$ \\
\hline $\mathrm{HbA1C}(\%)$ & 3.90 & 5.60 & $4.82 \pm 0.25$ & $5.09 \pm 0.22$ & $\begin{array}{l}< \\
0.001^{* *}\end{array}$ \\
\hline HOMA- $\beta$ & 54.60 & 601.83 & $133.53 \pm 51.56$ & $122.76 \pm 87.97$ & 0.106 \\
\hline HOMA-IR & 0.38 & 10.29 & $1.54 \pm 0.71$ & $2.43 \pm 1.58$ & $\begin{array}{l}< \\
0.001^{* *}\end{array}$ \\
\hline Matsuda & 0.86 & 18.01 & $32.37 \pm 13.56$ & $21.33 \pm 9.20$ & $\begin{array}{l}< \\
0.001^{\star *}\end{array}$ \\
\hline CPauc & 446.40 & 2907.90 & $981.15 \pm 322.46$ & $\begin{array}{l}1187.69 \pm \\
400.53\end{array}$ & $0.014^{*}$ \\
\hline INSauc & 1353.60 & 32004.30 & $\begin{array}{l}4934.84 \pm \\
3125.91\end{array}$ & $\begin{array}{l}6795.46 \pm \\
5057.21\end{array}$ & 0.058 \\
\hline \multicolumn{6}{|c|}{${ }^{\star} p<0.05 ; * \star p<0.01$} \\
\hline \multicolumn{6}{|c|}{ BMI: body mass index;GDM: Gestational Diabetes Mellitus;HbA1c: Glycosylated hemoglobin; } \\
\hline \multicolumn{6}{|c|}{ Fins: Fasting Insulin; Ins60: OGTT 1-Hour Insulin; Ins120: OGTT 2-Hour Insulin; } \\
\hline \multicolumn{6}{|c|}{ FCP: Fasting C peptide; CP60: OGTT 1-Hour C peptide; CP120: OGTT 2-Hour C peptide; } \\
\hline \multicolumn{6}{|c|}{ FBG: Fasting Glucose; BG60: OGTT 1-Hour Glucose; BG120: OGTT 2-Hour Glucose; } \\
\hline \multicolumn{6}{|c|}{ UCPS0: Fasting UCPS; UCPS120: OGTT 2Hour UCPS; } \\
\hline \multicolumn{6}{|c|}{ HOMA- $\beta$ : Homeostasis model assessment of beta cell function; } \\
\hline \multicolumn{6}{|c|}{ HOMA-IR: Homeostasis model assessment for insulin resistance; } \\
\hline
\end{tabular}

3.2. Fins, FCP, BMI (before pregnant), UCPS120, CPauc, Matsuda index and HOMA-IR of GDM group were higher than NGT group (Table 1).

3.3. FCP was correlated with UCPSO ( $r=0.243, p=0.002)$ and HOMA- $\beta(r=0.251, p=0.001)($ Figure $1 A, 1 B)$.

3.4. UCPS120 was correlated with Matsuda index $(r=-0.362, p<0.001)$ and HOMA-IR $(r=0.336, p<0.001)$ (Figure 2A, 2B).

3.5. UCPS120 was correlated with CPauc $(r=0.176, p<0.001)$ (Figure3). 
3.6. To predict the GDM, we try to use the simple and non-invasive index, so BMI, UCPS120, HOMA-IR and Matsuda index are put into the model. The combination of BMI and UCPS120 was better than other index, with a sensitivity of $72.0 \%$ and specificity of $70.7 \%$ (Table 2, Figure 4).

Table 2

ROC analysis to assess the predictive ability for GDM of each index

\begin{tabular}{|llllll|}
\hline variable & AUC & Standard error & $P$ & \multicolumn{2}{c|}{ 95\% credibility interval } \\
\cline { 5 - 6 } & & & & lower & upper \\
\hline BMI & 0.713 & 0.043 & $<0.001$ & 0.628 & 0.799 \\
\hline UCPS120 & 0.670 & 0.053 & 0.001 & 0.567 & 0.774 \\
\hline HOMA-IR & 0.735 & 0.043 & $<0.001$ & 0.651 & 0.819 \\
\hline Matsuda & 0.752 & 0.042 & $<0.001$ & 0.669 & 0.834 \\
\hline BMI + UCPS120 & 0.762 & 0.042 & $<0.001$ & 0.679 & 0.846 \\
\hline BMI + HOMA-IR & 0.763 & 0.039 & $<0.001$ & 0.687 & 0.839 \\
\hline BMI + Matsuda & 0.757 & 0.042 & $<0.001$ & 0.676 & 0.839 \\
\hline BMI: body mass index;GDM: Gestational Diabetes Mellitus; UCPS120: OGTT 2Hour UCPS; & \\
\hline HOMA- $\beta$ : Homeostasis model assessment of beta cell function; & \\
\hline HOMA-IR: Homeostasis model assessment for insulin resistance;
\end{tabular}

\section{Discussion}

UCPS is a new index adopted in this study, which reflects the total secretion of C-peptide in urine within a certain period of time, while different from UCPCR. In our study, UCPSO was associated with FCP and HOMA- $\beta$, but the $r$ value was low. In other study, they asked all the women to pass their overnight first void urine and collect the second void urine. We didn't emphasize to collect the second void urine, it may resulted in some discrepancy. UCPS120 of OGTT was correlated with CPauc, Matsuda index and HOMAIR, and the Matsuda index had the strongest correlation. Previous study showed that Matsuda index had stronger correlation with hyperinsulinaemic-euglycaemic clamp in pregnant women [10]. Although UCPCR120 only had weak correlation with Matsuda index, due to the small sample size, it still had the potential to be a new index to reflect insulin sensitivity in pregnant women.

Comparing the indexes of the two groups, it was found that the BMI, UCPS120, Fins, FCP, CPauc, Matsuda index and HOMA-IR of the GDM group were significantly higher than the NGT group. In all of these indexes, the calculation of CPauc, Matsuda index and HOMA-IR requires more parameters. The determination of these parameters requires multiple blood tests. while BMI and UCPS120 are noninvasive ones. HOMA-IR and Matsuda index had better predictions for GDM in previous studies [11, 12]. 
Recently researches showed that the pregnant women with high BMI before pregnancy had significantly high risk in GDM [13]. And pregnancy high BMI may be the independent risk factor for GDM [14]. We hope to use effective, simple and best non-invasive index to predict the GDM. So we choose BMI, UCPS120, HOMA-IR and Matsuda index. ROC curve analysis showed that to predict the GDM, the combination of $\mathrm{BMI}$ and UCPS120 was better than other index, with a sensitivity of $72.0 \%$ and specificity of $70.7 \%$. Many hospitals in china now advocate $75 \mathrm{~g}$ OGTT for all pregnant women, but multiple blood collection during pregnancy may cause problems for some women. If non-invasive tests can be used to screen out highrisk groups, and then OGTT tests for high-risk groups, it may help to reduce the psychological pressure of pregnant women, but also to save medical resources.

There are still some limitations in this study, all women included were in the second trimester of pregnancy (20-28 weeks), and the sample size was small. The conclusion needs to be expanded to verify the sample size. Secondly, the women included in this study were all with normal renal function, and the effect of different renal function status on this index could not be determined. There is increasing evidence that lifestyle and therapeutic intervention after 18 weeks of pregnancy in at-risk women has little effect on preventing both GDM and fetal macrosomia [15-18]. Further studies on a larger scale are needed, such as women with different renal function states in the early stage of pregnancy, to evaluate whether UCPS can be applied to women in early pregnancy to facilitate early screening of high-risk populations and early intervention.

\section{Conclusion}

UCPS120 had the potential to be a new index to reflect insulin sensitivity in pregnant women. To screening the GDM, the combination of BMI and UCPS120 was better than other index.

\section{Abbreviations}




\begin{tabular}{|ll|}
\hline GDM & gestational diabetes mellitus \\
\hline UCPs & Urinary C-peptide secretion \\
\hline OGTT & Oral glucose tolerance test \\
\hline HOMA-IR & Homeostasis model assessment for insulin resistance \\
\hline UCPCR & Homeostasic model assessment of beta cell function \\
\hline AUC & Arinary C peptide/creatinine ratio \\
\hline SPSS & Statistical package for the social sciences \\
\hline BMI & Body mass index \\
\hline Fins & Fast insulin \\
\hline FCP & Fast C-peptide \\
\hline FBG & Fast blood glucose \\
\hline Ins & Insulin \\
\hline CP & C peptide \\
\hline BG & Blood glucose \\
\hline HbA1C & Glycosylated hemoglobin \\
WHO & Worls health orgnision \\
\hline ADA & American diabetes association \\
CDS & Chianese diabetes society \\
UCR & Urinary creatinine \\
\hline ROC & Receiver operator characteristic curve \\
\hline HPLC & High pressure liquid chromatography \\
\hline
\end{tabular}

\section{Declarations}

\section{Ethics approval and consent to participate}

This study was approved by Wuhu Second People's Hospital Ethics Committee, and all enrolled participants had signed the informed consent.

\section{Consent for publication}

Not applicable 


\section{Competing interests}

There is no conflict of interest to disclose.

\section{Funding}

This research received a grant from Wuhu City Second People's Hospital.

\section{Authors' contributions}

WZ and XHM performed the collection of clinical specimens. All authors contributed to the concept and writing of the article. All authors read and approved the final manuscript.

\section{Acknowledgments}

We acknowledge the support of the endocrinology department of Wuhu City Second People's Hospital.

\section{Availability of data and materials}

Data sharing is not applicable to this article as no datasets were generated for the current study.

\section{References}

1. Agha Jaffar R, Oliver N, Johnson D, Robinson S. Gestational diabetes mellitus: does an effective prevention strategy exist? Nat Rev Endocrinol. 2016;12:533-46.

2. Buchanan TA, Xiang A, Kjos SL, et al. Gestational diabetes: antepartum characteristics that predict postpartum glucose intolerance and type 2 diabetes in Latino women. Diabetes. 1998;47:1302-10.

3. Das S, Behera MK, Misra S, et al. $\beta$-Cell Function and Insulin Resistance in Pregnancy and Their Relation to Fetal Development. Metabolic Syndrome Related Disorders. 2010;8(1):25-32.

4. Matthews DR, Hosker JP, Rudenski AS, Naylor BA, Treacher DF, Turner RC. Homeostasis model assessment: insulin resistance and beta-cell function from fasting plasma glucose and insulin concentrations in man. Diabetologia. 1985;28:412-9.

5. Matsuda M, DeFronzo RA. Insulin sensitivity indices obtained from oral glucose tolerance testing: comparison with the euglycemic insulin clamp. Diabetes Care. 1999;22:1462-70.

6. Leighton E, Sainsbu RY CA, Jones GC, et al. A practical review of c-peptide testing in diabetes. Diabetes Ther. 2017;8(3):475-87.

7. Wu Qiang L, Jun Z, Huan zhang, et al. Correlation between single point UCPCR and $24 \mathrm{~h}$ urine $\mathrm{C}$ peptide and islet function. Chinese Journal of Endocrinology Metabolism. 2012;28(1):24-5.

8. Oram RA, Rawlingson A, Shields BM, et al. Urine C-peptide creatinine ratio can be used to assess insulin resistance and insulin production in people without diabetes: an observational study. BMJ Open. 2013;3:e003193. 
9. Thomas NJ, Shields BM, Besser RE, et al. The impact of gender on urine C-peptide creatinine ratio interpretation. Ann Clin Biochem. 2012;49:363-8.

10. Kirwan JP, Huston-Presley L, Kalhan SC, et al. Clinicaly useful estimates of insulin sensitivity during pregnancy: validation studies in women with normal glucose tolerance and gestational diabetes mellitus. Diabetes Care. 2001;24:1602-7.

11. Yang SJ, Hwang SY, Baik SH, et al. Serum magnesium level is associated with type 2 diabetes in women with a history of gestational diabetes mellitus: the Korea National Diabetes Program study. J Korean Med Sci. 2013;29(1):84-9.

12. Yang SJ, Kim TN, Baik SH, et al. Insulin secretion and insulin resistance in Korean women with gestational diabetes mellitus and impaired glucose tolerance. Korean J Intern Med. 2013;28(3):30613.

13. National Institutes of Health consensus development. conference statement: diagnosing gestational diabetes mellitus, March 4-6, 2013. Obstet Gynecol 2013; 122: 358-369.

14. Ying P, Ji Hu1, Zhong S. The joint prediction model of pBMI and eFBG in predicting gestational diabetes mellitus. J Int Med Res. 2019;10:1-7.

15. Briley AL, Barr S, Badger S, et al. A complex intervention to improve pregnancy outcome in obese women; the UPBEAT randomized controlled trial. BMC Pregnancy Childbirth. 2014;14:74.

16. Syngelaki A, Nicolaides KH, Balani J, et al. Metformin versus Placebo in Obese Pregnant Women without Diabetes Mellitus. N Engl J Med. 2016;374:434-43.

17. Simmons D, Devlieger R, van Assche A, et al. Effect of physical activity and/or healthy eating on GDM Risk: The DALI lifestyle study. J Clin Endocrinol Metab. 2017;102:903-13.

18. Wang S, Ma JM, Yang HX. Lifestyle intervention for gestational diabetes mellitus prevention: A cluster-randomized controlled study. Chronic Dis Transl Med. 2015;1:169-74.

\section{Figures}


A.

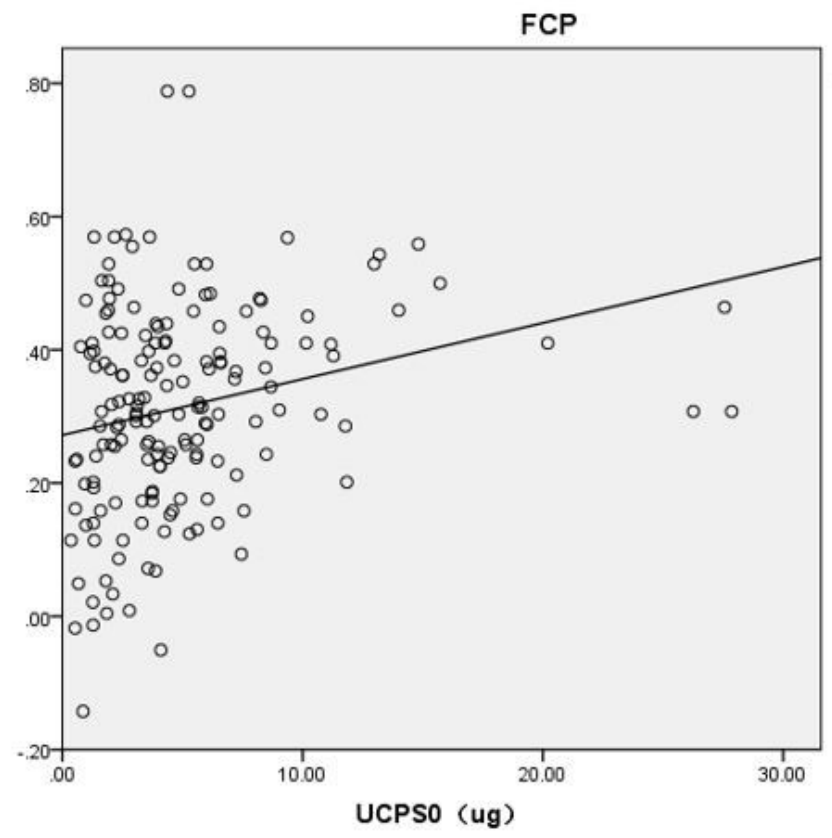

- observed - linear
B.

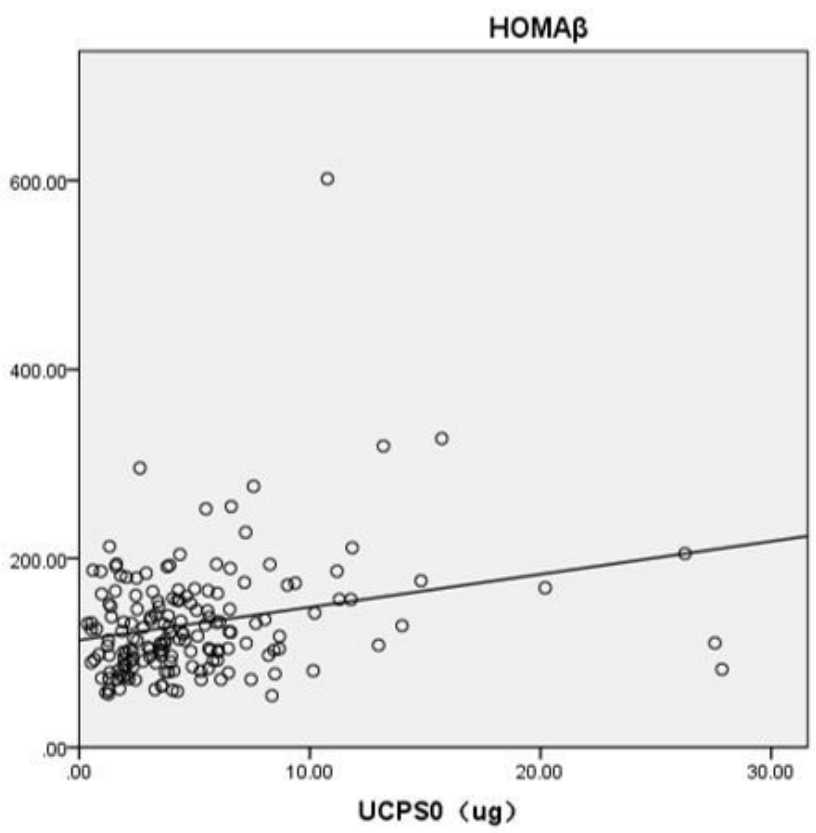

- observed — linear

\section{Figure 1}

A. Linear regression model for UCPSO and $F C P, Y=0.272+0.08 X, r=0.243, p=0.002$. B. Linear regression model for UCPSO and HOMA $\beta, Y=113.434+3.487 X, r=0.251, p=0.001$, FCP: fasting $C$ peptid, UCPS0: fasting urinary $\mathrm{C}$ peptide secretion.

A.

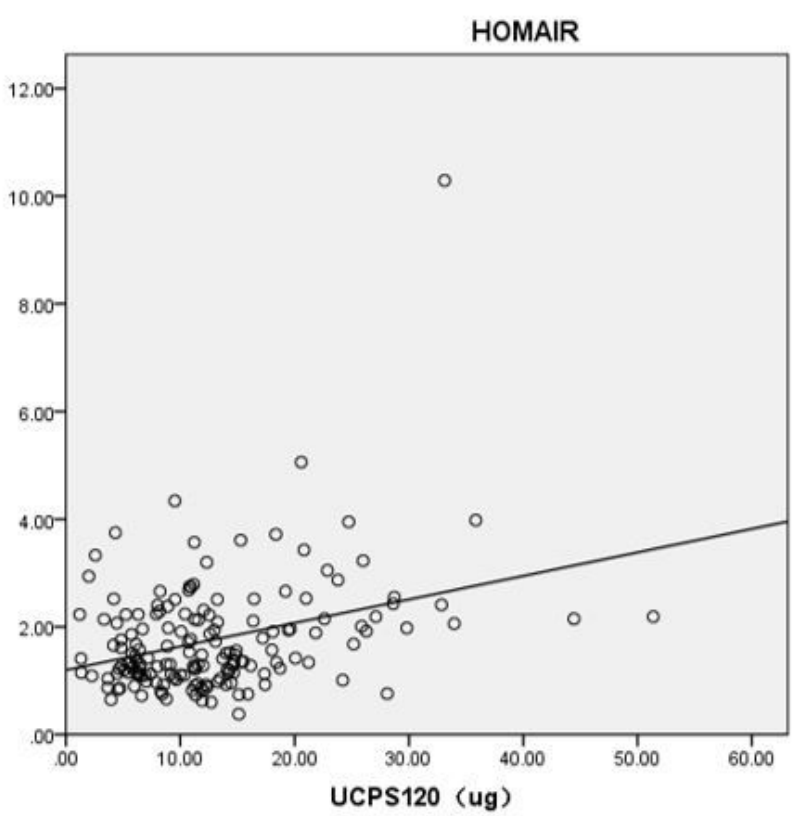

- observed - linear
B.

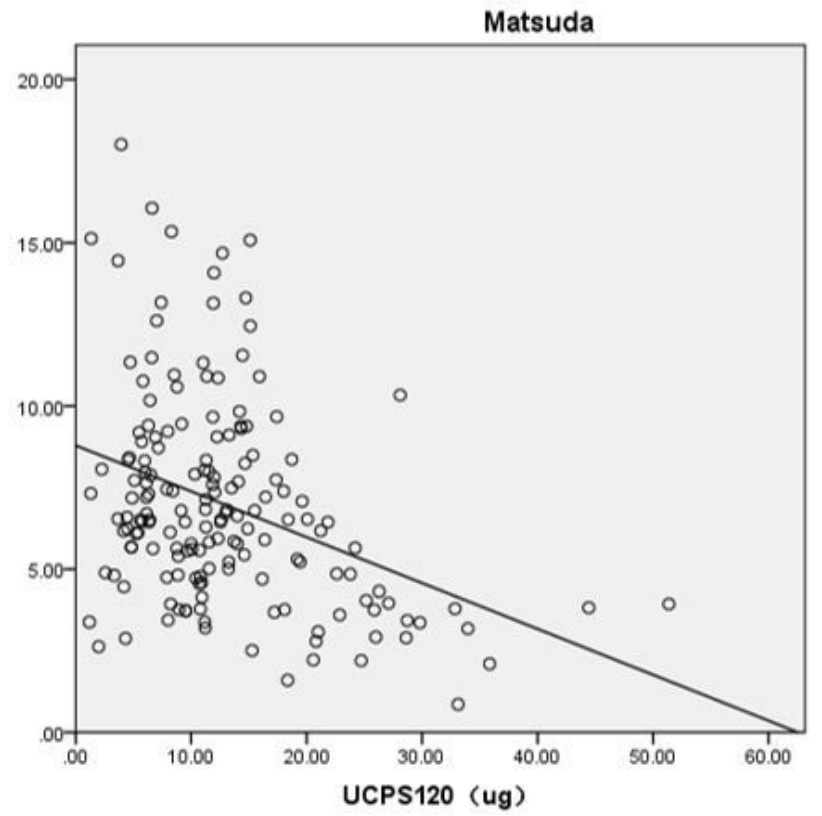

- observed - linear 
Figure 2

A. Linear regression model for UCPS120 and HOMA IR, $Y=1.199+0.44 X, r=0.336, p<0.001$. B. Linear regression model for UCPS120 and Matsuda, $Y=8.790-0.141 \mathrm{X}, \mathrm{r}=-0.362, \mathrm{p}<0.001$. UCPS120: OGTT $2 \mathrm{~h}$ urinary $\mathrm{C}$ peptide secretion.

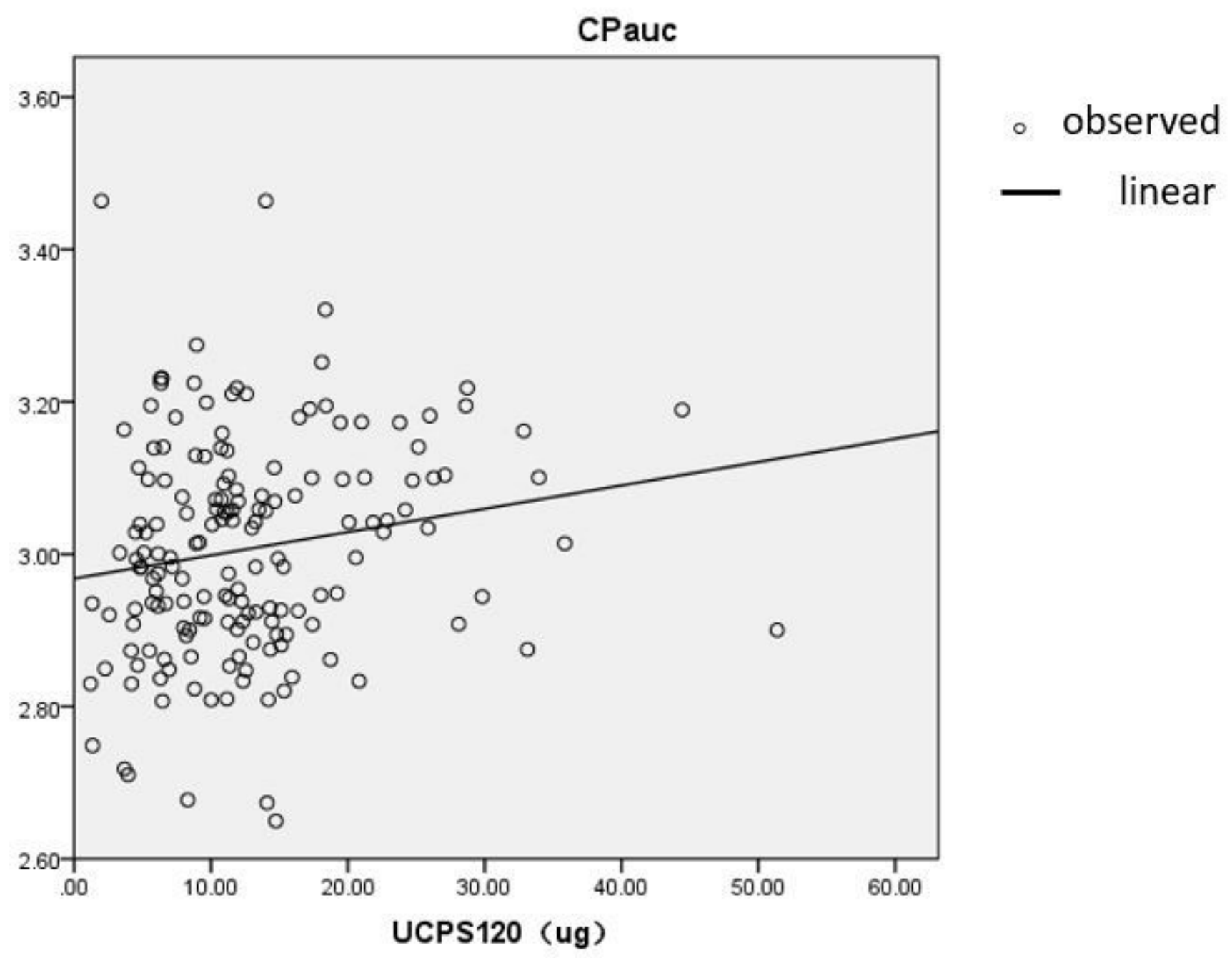

Figure 3

Linear regression model for UCPS120 and CPauc, $Y=2.968+0.003 \mathrm{X}, \mathrm{r}=0.176, \mathrm{p}=0.012$. CPauc: area under the serum C-peptide curve $C$ peptide, UCPS120: OGTT $2 \mathrm{~h}$ urinary $\mathrm{C}$ peptide secretion. 


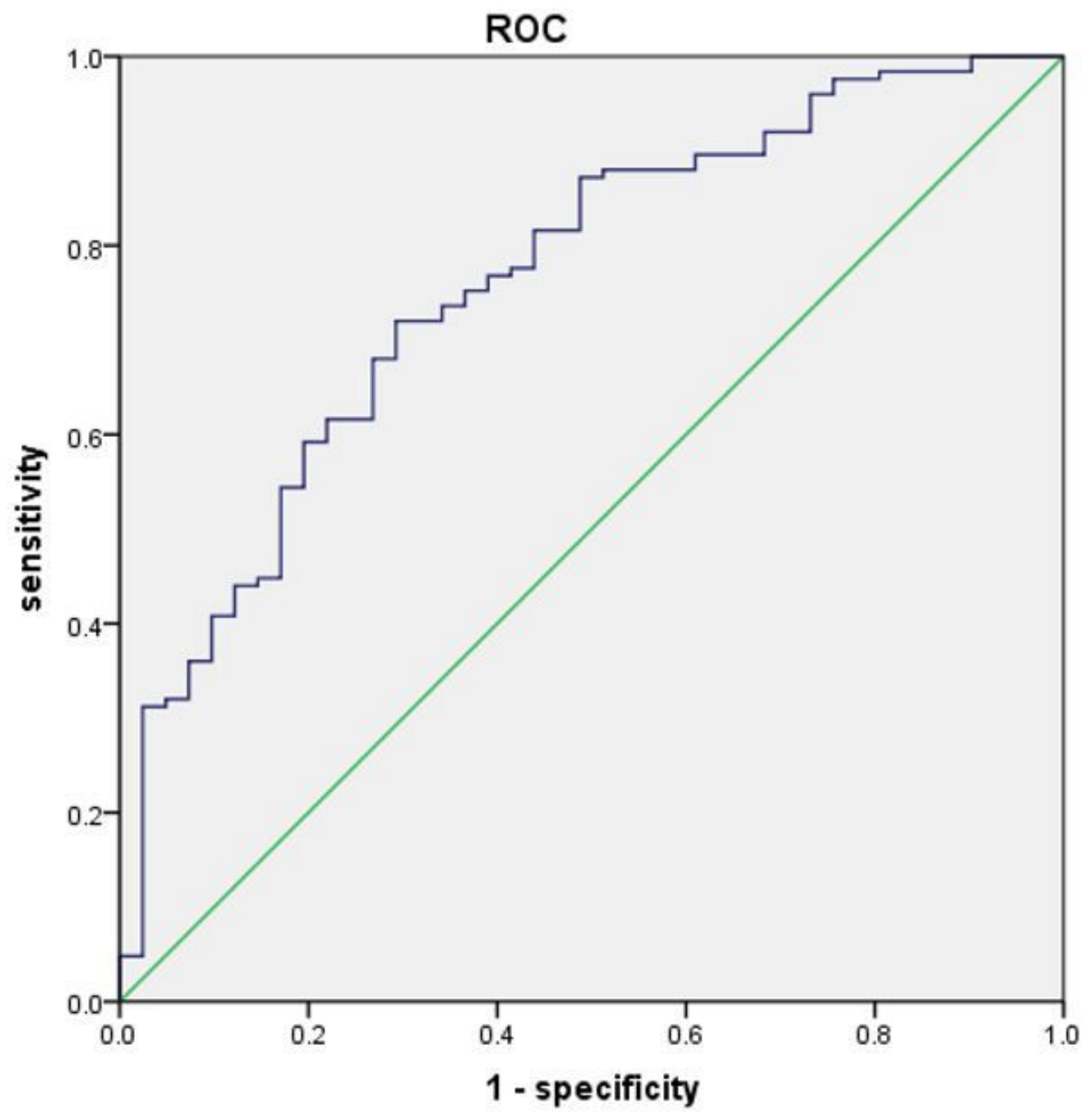

Figure 4

ROC of BMI combined with UCPS120 to predict the GDM 